\title{
Multi-body Dynamical Modeling and Co-simulation of Active front Steering Vehicle
}

\author{
Feng Ying \\ Dept. of Automotive Engineering \\ Hubei Automotive Industries Institute \\ Shiyan Hubei, China
}

\author{
Zhang Qiao \\ Dept. of Automotive Engineering \\ Hubei Automotive Industries Institute \\ Shiyan Hubei, China
}

\begin{abstract}
With the help of ADAMS, a dynamical model of the active front steering system with double planetary gear mechanism and the whole vehicle model were built. Based on fuzzy control theory, the fuzzy control strategy for the vehicle with an active front steering system was put forward, the proposed AFS took the side slip angle of mass centre and yaw rate of the vehicle as fuzzy control rule input, and the output was the motor angle in the active front steering system. The co-simulation of the contro1 system and the vehicle model was realized through the data exchanging between ADAMS and Matlab, then the dynamic response of the vehicle with active front steering under typical driving condition was simulated. The research results showed that the method of fuzzy control can control the yaw rate and the side-slip angle of mass centre, therefore lateral stability of vehicle is further improved.
\end{abstract}

Keywords-active front steering, multi-body dynamics, fuzzy control, co-simulation

\section{INTRODUCTION}

Steering system is an important component for lane changing control of wheeled vehicles. Its performance influences vehicle steer ability and stability directly. Active Front Steering (AFS) provides an electronically controlled superposition of an angle to the steering wheel angle. This additional degree of freedom enables a continuous and driving-situation dependent adaptation of the steering characteristics. Features like steering comfort, effort and steering dynamics are optimized and stabilizing steering interventions can be performed[1]. As a result, the AFS system provides the vehicle with a new standard of driving agility, amenity and safety. It is the trend in development of the steering system.

In this paper, a dynamical model of the active front steering system with double planetary gear mechanism and the whole vehicle model are built up in ADAMS/Car, the AFS fuzzy control model is built in Matlab/Simulink, and the control strategy is designed with the help of fuzzy control tool boxes. The vehicle model and the control model are integrated through ADAMS/Control module, and the co-simulation is carried out for the typical driving cycles. Finally, the simulation results verify the reasonability of the control algorithm and provide references for the vehicle system parameter matching.

\section{MULTI-BODY VEHICLE MODEL}

The vehicle dynamic model is built up by down-top modeling method with the help of ADAMS/Car. Firstly, the templates are built up, then the subsystems are built up based on the templates, and the whole vehicle is finally assembled [2].

\section{A. Active steering system modeling}

AFS consists of rack and pinion steering system, double planetary gears, motor, ECU and sensors. The double planetary gears integrated on the steering column are the core parts of AFS, which has two planetary gears (upper and lower) sharing one carrier, as shown in Figure. 1. The input sun gear connected with steering wheel transmits the steering angle of steering wheel to planetary gear 2 through carrier 3, and the output sun gear is connected with output shaft 9. As the upper planetary gear pair has two input DOFs: one DOF is the steering angle of steering wheel 5 transmitted by the upper sun gear, another DOF is the input of ring gear 4 driven by the motor through a self-locked worm and gear, then the output steering angle is determined by the steering angle of steering wheel and the angle of ring gear driven by the motor. The relationship [3] between the speed of output shaft 9 and the speed of the steering wheel 5 and motor 8 is:

$$
\omega_{9}=\omega_{5}+\frac{\alpha_{1}}{i_{M}} \omega_{8}
$$

Where $\omega_{9}$ is the speed of output shaft, $\omega_{5}$ is the speed of steering wheel, $\omega_{8}$ is the speed of motor, $\alpha_{1}$ is the ratio of gear teeth between ring gear 4 and input sun gear, $i_{M}$ is the gear ratio of worm and gear.

To build up the AFS steering template, the first thing is to simplify the steering system, and then to determine the topology structure of the steering system. Finally the hardpoints, parts and attachments are built up in the template. The parts are attached to each other by joints or bushings. The whole AFS consists of 21 moving parts (including 3 mount parts and 1 switch parts), 15 revolute joints, 2 hooker joints, 1 translational joint, 7 fixed joints and 1 inplane primitive joint, and 4 gears, 2 couplers and 2 motions. To realize the co-simulation between ADAMS and Matlab, the motor angle is set as input variant in the steering template, and the angle value is from the AFS fuzzy 
controller. The AFS subsystem is built up based on the steering template.

\section{B. Vehicle multi-body dynamic model}

All the subsystems built are assembled with the vehicle test rig in the standard interface to get the vehicle multi-body dynamic simulation model, as shown in figure 2(hiding the body subsystem and power train subsystem), the other subsystems are: the front suspension subsystem is a Macpherson suspension, the rear suspension subsystem is a multi-link suspension[4], the braking subsystem is hydraulic disc brakes, the tire model is the classic Magic Formula tire model, the power train subsystem is an engine with line four cylinders, F.F layout. The whole vehicle and steering subsystem main parameters are listed Table. 1.

\section{AFS FUZZY CONTROLLER DESIGN}

\section{A. Co- control structure}

The vehicle handing stability control includes stability control and road tracing performance. Generally, the former is illustrated by yaw velocity, and the latter can be illustrated by sideslip angle, the two control variants are mutual coupling. Based on this, the AFS control system adopts yaw velocity and sideslip angle integrated control method, and yaw velocity $\omega$ and sideslip angle $\beta$ two fuzzy controllers are designed through the comparison of the output variants of the actual vehicle and the desired vehicle, as shown in figure 3 .

In the figure 3 , the simulation initial conditions are the steering wheel angle $\delta_{\mathrm{sw}}$ and initial velocity $\mathrm{v}$, the output variants of the ADAMS model are lateral acceleration $\dot{v}_{y}$, longitudinal velocity $\mathrm{v}_{\mathrm{L}}$ and yaw velocity $\omega$, which are set as the input variants of the Matlab model. Firstly, the sideslip angle $\beta$ of the actual vehicle is calculated through the sideslip angle estimator, then the sideslip angle $\beta$ and yaw velocity $\omega$ are compared with each other's desired values $\beta_{\mathrm{d}}$ and $\omega_{\mathrm{d}}$, the error and error rate are the input variants of the fuzzy controllers, the corresponding output variants are calculated according to the fuzzy rules and weighted in order to adjust the motor angle, which is set as the input variant of the ADAMS model to control AFS.

\section{B. Desired vehicle sideslip angle and yaw velocity}

Many papers take the steering characteristics of the linear 2-DOF vehicle model as the desired steering characteristics, for it can reflect the linear relationship between the steering inputs of driver and yaw velocity[5]. The desired yaw velocity can be calculated by formula (3) according to the linear 2-DOF reference model.

$$
\omega_{\mathrm{d}}=\frac{v}{L\left(1+K v^{2}\right)} \delta
$$

In the formula (3), the $K=\frac{m}{L^{2}}\left(\frac{a}{k_{r}}-\frac{b}{k_{f}}\right)$ is a vehicle stability factor, the a is the distance between C.G. and front axle, the $b$ is the distance between C.G. and rear axle, the $\mathrm{L}$ is the wheelbase, the $\mathrm{m}$ is the vehicle mass, the $k_{\mathrm{f}}$ and $k_{\mathrm{r}}$ are the front and rear tires lateral stiffness respectively, the lateral stiffness calculated according to Magic Formula under the condition of static load is applied to the co-simulation. The $\mathrm{v}$ is vehicle velocity.

At present, the vehicle sideslip angle is generally estimated, which is estimated with formula (4) in this paper.

$$
\beta=\frac{\dot{v}_{y}}{v_{L}}-\omega
$$

The vehicle sideslip angle $\beta$ should be controlled as small as possible. The desired vehicle sideslip angle $\beta_{\mathrm{d}}$ is set to 0 .

\section{Fuzzy control design}

In order to achieve satisfactory results, the fuzzy control realizes fuzzy reasoning and makes fuzzy judgments and decisions by simulating human thinking and control experience. Fuzzy control design mainly includes the structure choice of the fuzzy controller, the definition of the fuzzy control rules, the decision of the fuzzification and defuzzification, and the selection of the quantization domain. Fuzzy controller is designed in this paper through Matlab/Fuzzy Logic Tool boxes.

The two fuzzy subsets of the input and output language variants are all $\{\mathrm{NB}, \mathrm{NM}, \mathrm{NS}, \mathrm{ZE}, \mathrm{PS}, \mathrm{PM}, \mathrm{PB}\}$, where NB, NM, NS stands for negative big, negative middle and negative small respectively; ZE stands for 0; PS PM, PS stands for positive small, positive middle and positive big. Quantization domain [-1, +1], membership functions are all trimf, which is simple, suitable for real-time co-simulation and can meet the control accuracy.

Fuzzy control rules are the important components of the fuzzy controller, and these rules describe the fuzzy relationship with language between the input and output variants of the controller. Fuzzy control rules are generated in the way of fuzzy reasoning according to human experience. Two input variants of each controller are described in 7 language fuzzy subsets, forming 49 control rules. The final control rules of the fuzzy controller are listed in Table. 2 and Table. 3 respectively. The control algorithm of the system adopts the mandani method, and the fuzzy decision adopts the biseclor method.

\section{ADAMS\&MATLAB CO-SIMULATION CONTROLS}

In order to verify the rationality and validity of the system models, control strategy and simulation algorithm, the vehicle model and the control model are integrated 
through ADAMS/Control module, and the co-simulation is carried out for the typical driving cycles.

For the driving condition, the steering wheel angle input is the single periodic sine signal, the simulation time is $6 \mathrm{~s}$, the start time is $1 \mathrm{~s}$, the Max steering wheel input is $72 \mathrm{deg}$, the frequency is $0.5 \mathrm{~Hz}$, and the initial vehicle velocity is $90 \mathrm{~km} / \mathrm{h}$. The road attachment coefficient is the wet $\operatorname{road}(\varphi=0.5)$. The simulation results are illustrated in figure 4-7.

As shown in figure 4 , the response curve is motor angle vs. time with fuzzy control. As shown in figure 5, when the fuzzy integrated control is applied to the AFS vehicle, the actual vehicle velocity can trace the desired vehicle yaw velocity very well; as shown in figure 6 , the AFS vehicle sideslip angle is also effectively inhibited. The AFS vehicle response with fuzzy integrated control is better than the FWS vehicle without fuzzy integrated control. As shown in figure 7 , the sideslip angle vs. yaw velocity phase diagram curve of the FWS vehicle is not closed, which is the response of vehicle with great instability because of the reason the sideslip angle increases quickly when the vehicle takes a sharp turn in the wet road. On the contrary, the phase diagram curve of the AFS vehicle is closed and the result turns out to be stable. Thus the yaw velocity and sideslip angle integrated control based on fuzzy control not only improves the vehicle handling stability, but also assures the road tracing performance well by the way of providing an electronically controlled superposition of a motor angle which is weighted to the steering wheel angle.

\section{CONCLUSIONS}

AFS and the vehicle multi-body dynamic model are built up in ADAMS/Car, and the motor control of AFS is realized through the co-simulation between ADAMS and Matlab/Simulink, the conclusions include:

1) The AFS vehicle multi-body dynamic model built provides references for the research in AFS vehicle stability control.

2) The yaw velocity and sideslip angle fuzzy controller are designed to get vehicle a high stability, meanwhile, the road tracing performance and the handling stability are improved effectively.

The simulation results show that the control algorithm are correct, and provide references for further actual vehicle test and the research in integrated control system of steering \& braking.

\section{REFERENCE:}

[1] Gao Xiaojie, Yu Zhuoping, Zhang Lijun, et a1.The principle and application of mechanical active front steering system[J].Automotive Engineering.2006(10):918-921.

[2] Chen Jun. Technique and engineering analysis example based on MSC.ADAMS. China WaterPower Press. 2008.

[3] Chen Deling. Investigation to control of an active front steering system [D]. Shanghai Jiao Tong University.2008.

[4] Feng Ying, Guo Yiming, Zheng Dongli, et al.Modeling and handling stability simulation of full vehicle based on ADAMS software[J].Journal of Hubei Automobile Industries Institute: 2009(3):5-10.

[5] Feng Ying, Guo Yiming, Zhou Hongni. Control for Vehicle Handing Stability Based on ADAMS and Matlab[C],The 2010 International Conference on Computer Application and System Modeling. TaiYuan, China,546-549.

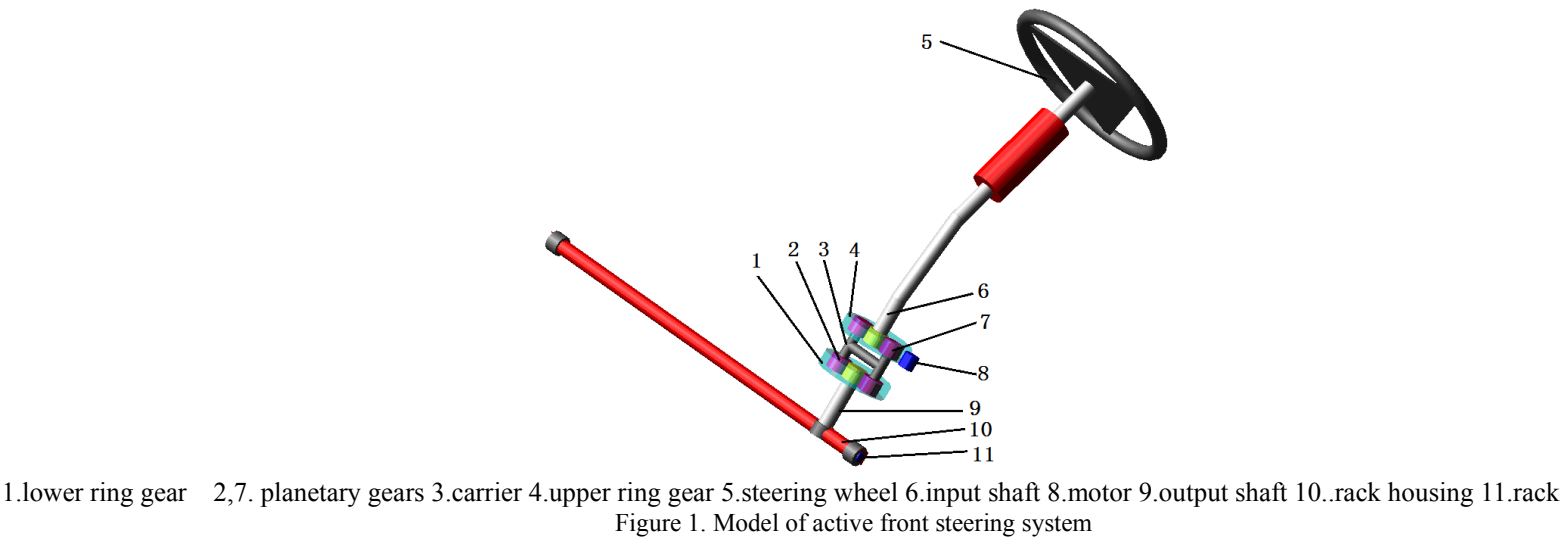

Figure 1. Model of active front steering system 
TABLE. I PRIMARY PARAMETERS OF VEHICLE AND STEERING SYSTEM

\begin{tabular}{|c|c|c|c|}
\hline vehicle mass $/ \mathrm{kg}$ & 1800 & z-axle inertial $/ \mathrm{kg} \cdot \mathrm{m}^{2}$ & 4116 \\
\hline wheelbase $/ \mathrm{mm}$ & 2560 & $\begin{array}{l}\text { the distance between C.G. } \\
\text { and front axle } / \mathrm{mm}\end{array}$ & 1240 \\
\hline C.G. height/mm & 500 & steering gear ratio & 18 \\
\hline planetary gears ratio $\alpha_{1}$ & 3 & worm and gear ratio $\omega_{1}$ & 25 \\
\hline
\end{tabular}
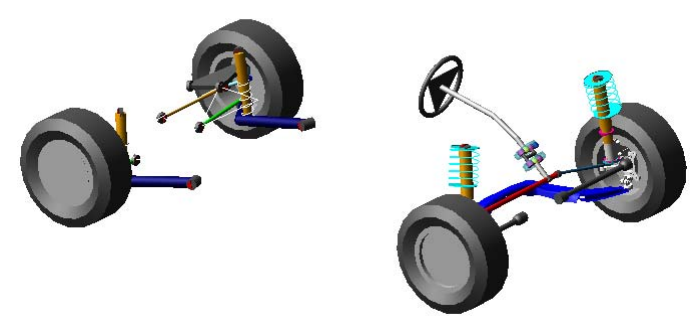

Figure 2. Vehicle model

TABLE II. FUZZY CONTROLLER RULES OF YAW VELOCITY

\begin{tabular}{|c|c|c|c|c|c|c|c|c|}
\hline \multirow{2}{*}{$\delta_{\mathrm{M} 1}$} & & \multicolumn{7}{|c|}{$\mathrm{d} \Delta \omega / \mathrm{dt}$} \\
\hline & & $\mathrm{NB}$ & NM & NS & ZE & PS & PM & PB \\
\hline \multirow{7}{*}{$\Delta \omega$} & NB & $\mathrm{PB}$ & $\mathrm{PB}$ & $\mathrm{PB}$ & $\mathrm{PB}$ & PB & $\mathrm{PB}$ & PB \\
\hline & NM & PB & $\mathrm{PB}$ & PM & PM & PM & PM & PM \\
\hline & NS & PM & PM & PM & PS & PS & PS & ZE \\
\hline & ZE & ZE & ZE & ZE & ZE & ZE & NS & NS \\
\hline & PS & $\mathrm{ZE}$ & ZE & NS & NS & NM & NM & NM \\
\hline & PM & NS & NS & NM & NM & NB & NB & NB \\
\hline & PB & NM & NM & NM & NB & NB & NB & NB \\
\hline
\end{tabular}

TABLE III. FUZZY CONTROLLER RULES OF SIDE-SLIP ANGLE OF MASS CENTRE

\begin{tabular}{|c|c|c|c|c|c|c|c|c|}
\hline \multirow{2}{*}{$\delta_{\mathrm{M} 2}$} & & \multicolumn{7}{|c|}{$\mathrm{d} \Delta \beta / \mathrm{dt}$} \\
\hline & & $\mathrm{NB}$ & NM & NS & ZE & PS & PM & $\mathrm{PB}$ \\
\hline \multirow{7}{*}{$\Delta \beta$} & $\mathrm{NB}$ & $\mathrm{NB}$ & NB & $\mathrm{NB}$ & NB & $\mathrm{NB}$ & $\mathrm{NB}$ & $\mathrm{NB}$ \\
\hline & $\mathrm{NM}$ & NB & NB & NB & $\mathrm{NM}$ & $\mathrm{NM}$ & NM & $\mathrm{NM}$ \\
\hline & NS & $\mathrm{NM}$ & NM & $\mathrm{NM}$ & NS & NP & NS & ZE \\
\hline & ZE & ZE & ZE & ZE & ZE & ZE & ZE & ZE \\
\hline & PS & $\mathrm{ZE}$ & PS & PS & PS & PS & PM & PM \\
\hline & PM & PS & PM & PM & PM & PB & PB & PB \\
\hline & $\mathrm{PB}$ & PM & PM & $\mathrm{PB}$ & $\mathrm{PB}$ & $\mathrm{PB}$ & $\mathrm{PB}$ & $\mathrm{PB}$ \\
\hline
\end{tabular}




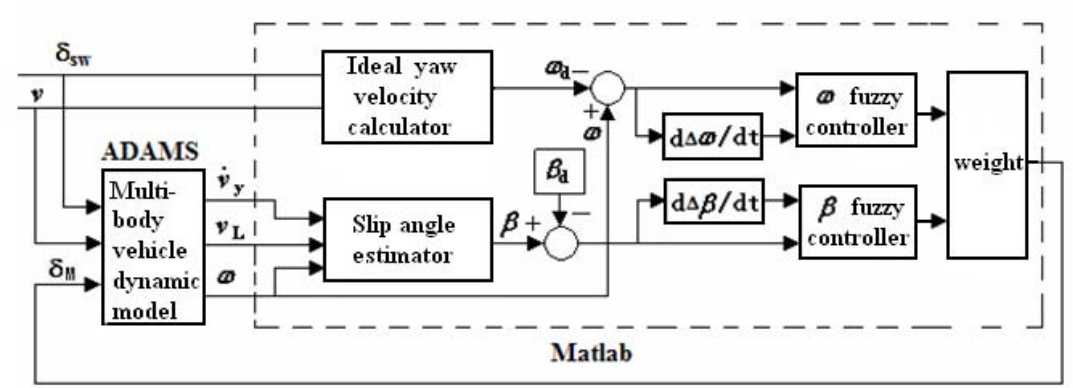

Figure 3. Co-control structure of AFS vehicle

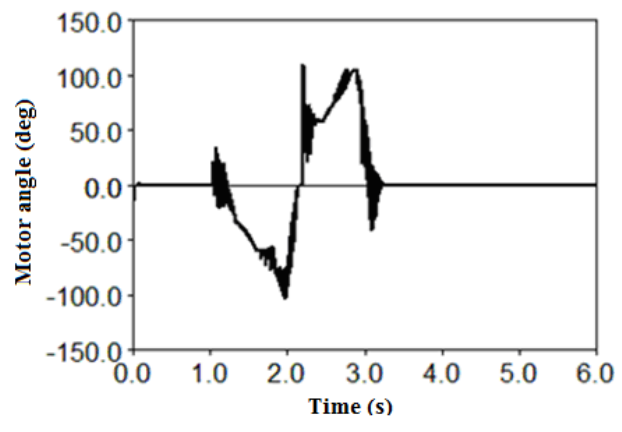

Figure 4. Angle of servo motor

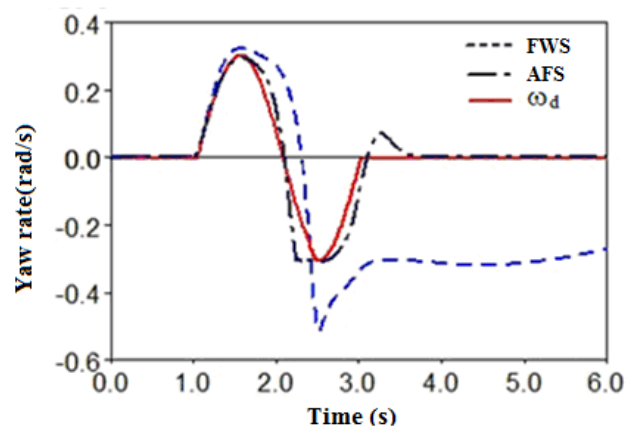

Figure 6. Comparison curves of side slip angle

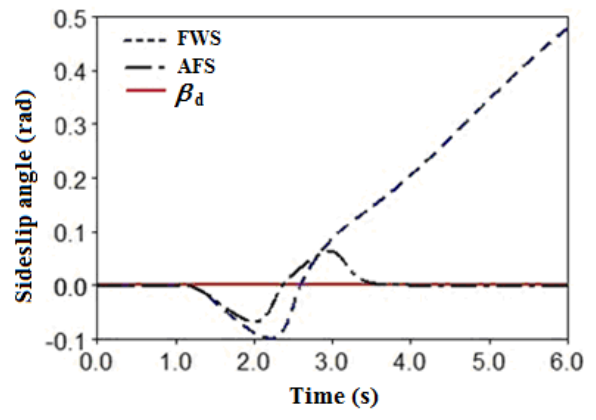

Figure 5. Comparison curves of yaw rate

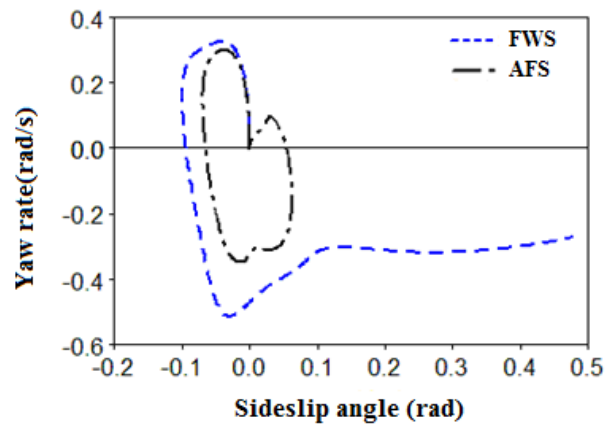

Figure 7. Phase diagram of side slip angle and yaw rate 